\title{
Bouncing forward: a resilience approach to dealing with COVID-19 and future systemic shocks
}

\author{
William Hynes ${ }^{1} \cdot$ Benjamin Trump ${ }^{1,2} \cdot$ Patrick Love $^{1} \cdot$ Igor Linkov $^{1,3}$ (C)
}

Published online: 25 May 2020

(c) This is a U.S. Government work and not under copyright protection in the US; foreign copyright protection may apply 2020

\begin{abstract}
Policy questions are often framed in popular discussion as situations where pulling the right levers will get the economy and society back on track after shocks and crises. This approach ignores how systems interact and how their systemic properties shape socioeconomic outcomes, leading to an over-emphasis on a limited set of characteristics, notably efficiency. We argue that this emphasis on efficiency in the operation, management and outcomes of various economic and social systems is not a conscious collective choice, but rather the response of the whole system to the incentives that individual components face. This has brought much of the world to rely upon complex, nested, and interconnected systems to deliver goods and services around the globe. While this approach has many benefits, the Covid-19 crisis shows how it has also reduced the resilience of key systems to shocks, and allowed failures to cascade from one system to others. This paper reviews the impact of COVID-19 on socioeconomic systems, discusses the notion of resilience, and provides specific recommendations on both integrating resilience analytics for recovery from the current crisis as well as on building resilient infrastructure to address future systemic challenges.
\end{abstract}

Keywords Covid-19 $\cdot$ Coronavirus $\cdot$ OECD $\cdot$ Resilience $\cdot$ Economic impact $\cdot$ Risk

"Everything we do before a pandemic will seem alarmist, everything we do after a pandemic will seem inadequate".

US Health and Human Services

Secretary Michael Leavitt in 2007.

\section{Introduction}

Even before the Covid-19 pandemic, we were living in a period of profound socioeconomic and environmental systemic change. As in similar periods in the past, there is bound to be considerable instability and uncertainty before the new society and economy take shape. In the meantime, we can identify actions that will shape change for the better, and help to build resilience to the inevitable shocks inherent in, and generated

Igor Linkov

Igor.Linkov@usace.army.mil

1 New Approaches to Economic Challenges Unit, Office of the Secretary General, OECD, 2 rue Andre Pascal, 75775 Paris, France

2 University of Michigan, Ann Arbor, MI, USA

3 Carnegie Mellon University, Pittsburgh, PA, USA by, the complex system of systems constituted by the economy, society, and the environment. These challenges require updating the way governments devise and implement policies. This in turn will require more realistic tools and techniques to design these policies than those that failed to anticipate previous crises or to help design sustainable solutions to them.

To tackle planetary emergencies linked to the environment, the economy, and socio-political systems, we have to understand their systemic properties. System resilience is a term of rising popularity during the Covid-19 pandemic, but we must not neglect other system properties such as tipping points, non-linearity, asymmetry, and interconnectedness. The systems approach can promote cross-sectoral, multidisciplinary collaboration in the process of policy formulation by taking proper account of the crucial linkages between issues generally treated separately within different specializations and scientific and institutional "silos." In order to promote positive social and economic change, a range of policies has to be integrated, including educational, demographic, employment, well-being, and technology and innovation policies. Systems thinking provides a methodology to achieve a better understanding of the behavior of complex systems and to improve the assessment of the consequences of policy interventions. 
Growing complexity and interdependence have made various systems (economic, public health, cyber, etc.) susceptible to widespread, irreversible, and cascading failure. Serious disease outbreaks such as Covid-19 are the result of systemic properties, and in this case, emergence in particular. Emergence describes a process whereby a situation arises through the interaction of a number of actors and influences, without any intention to create that situation. A recent paper published by the UK Royal Society (Johnson et al. 2020) shows that emerging infectious diseases in humans are frequently caused by pathogens originating from animal hosts, and that virus transmission risk is highest from animal species that have increased in abundance and even expanded their range by adapting to human-dominated landscapes. Among threatened wildlife species, those with population reductions because of exploitation and loss of habitat share more viruses with humans. In other words, impacts on ecosystems due to changes to socioeconomic systems, such as the introduction of intensive agriculture, play a role in creating or aggravating epidemic risk. One study looking at the emergence of infectious diseases calculated that since 1940, intensive agriculture has been associated with more than $25 \%$ of all infectious diseases that emerged in humans and more than half of all infectious diseases that spilled over from animals to humans (Rohr et al. 2019).

Striving for maximum efficiency and optimization, such systems have neglected resilience against disruptions (Marchese 2012) whose shocks may leave governments, the public, and the environment in a weakened state. More specifically, the concentration of industrial capacities and economic activity into smaller and more efficient sectors, up to the international level, has produced highly lucrative yet fragile supply chains, and economic exchanges whose disruptions could have sweeping effects in unexpected areas. While this has provided considerable opportunities, it has also made the systems we rely on in our daily lives (e.g., international supply chains) vulnerable to sudden and unexpected disruption, as the result of either an external shock, the way the system has self-organised, or a combination of both (Juttner and Maklan 2011; OECD and FAO 2019). The 2011 earthquake and tsunami in Japan, for example, exposed the limits of just-in-time supply chain organization, and highlighted the importance of flexibility, diversification, and adaptability (Fujimoto 2011; Golan et al. 2020).

Such notions have been thoroughly described by leading economists and scholars since the onset of the 2007-2009 financial crisis, yet primarily in an abstract context, although Andrew Haldane, the Bank of England's Chief Economist, did argue in 2009 that "the spread of epidemics and the disintegration of the financial system - each is essentially a different branch of the same network family tree" (Haldane 2009). A key question, therefore, is focused not upon whether systemic risk would cause substantial cascading losses to the international economy, but rather on what type of disruption would trigger such a chain of events in the first place. The Covid-19 outbreak has led to a crisis with considerable cascading losses for health but also for much of the global economy, with concordant high social costs. At the moment, national governments are struggling to absorb the shock generated by the pandemic, but in time the international community will overcome the crisis and begin the recovery phase.

Resilience, or the ability to recover from and adapt to unexpected threats, has been a focus of specific parts of our system, for instance military and public health authorities. But the notions of viability and resilience can be in tension with short-term profitability and apparent efficiency (Aubin 2010). The disastrous consequences of recent bush fires in Australia and extensive flooding in many parts of the world, both attributable to climate change, show that resilience must become a core philosophy within system management and operations to ensure we are able to continue to function in the midst of these disruptions, and particularly those aggravated by disruptions from Covid- 19 .

The policy response should be twofold: address immediate concerns, and propose an approach to dealing with the longer-term issues the pandemic highlights. In the short term, that means identifying the people and activities most affected, assessing how measures to help them will impact others, and underlining that difficult trade-offs between health, economic, social, and other goals are inevitable. In the longer term, an approach that reacts to the systemic origins and impacts of major shocks is needed if policies are to be effective. The Covid-19 crisis also shows how important it is to keep resources in reserve for times when unexpected upheavals in the system prevent it from functioning normally (and the argument can be made for not depleting natural resources). Furthermore, given the interdependence of our economies and social systems, the pandemic also highlights the need for strengthened international cooperation (building on existing frameworks for emergency preparedness) based on evidence to tackle systemic threats and help avert systemic collapse. ${ }^{1}$ Helbing (2012) and others have noted that the consequences of failing to appreciate and manage the characteristics of complex global systems and problems can be immense.

\footnotetext{
$\overline{1}$ The WHO inter alia has developed a strategic framework for emergency preparedness. After this epidemic crisis, no doubt the international community will have to reflect very seriously about how to bring health emergency preparedness to a new (much higher) level.
} 


\section{Economic and social impact of COVID-19}

Declared a pandemic by the World Health Organization (WHO) on March 11, 2020, Covid-19 quickly spread globally. The elderly disproportionality experience more negative health outcomes, but the effects on them result from more than just the medical conditions common to other at-risk groups, such as obesity, smoking, heart disease, and diabetes. A number of additional factors contribute to the total impact. The elderly are exceptionally exposed to death from the disease, but also risks arising from isolation and weak social ties, compounded by the fragmentation of health and social care services. School closures are the main impact on children and young people, but the capacity to compensate for the projected loss in learning varies according to socioeconomic status, with those from low-income and/or single-parent families likely to be the most affected by the closure of schools and childcare facilities. The PISA 2015 surveys (OECD 2016) reveal that nearly a quarter of 15 -year-olds of low socioeconomic status do not have an office or a quiet place to study; just over 1 in 5 teenagers in the same families have no access to a computer for school work or an internet connection. The poorest children are also suffering by being deprived of school meals and other support measures provided by or at schools.

The differing social impacts are one result of a number of economic trends that have already been shaping well-being for many years before the Covid-19 pandemic, notably the impacts of austerity, growing inequality, weakened social protection, and increased precariousness in labor markets (OECD 2011, 2018). The OECD Interim Economic Outlook, released on March 2, 2020, shows how restrictions on the movement of people, goods, and services, in combination with containment measures such as business closures, have cut manufacturing and domestic demand sharply in China, while also affecting the rest of the world through business travel and tourism, global supply chains, commodities, and loss of confidence. The initial direct impact of the shutdowns could be a decline in the level of output of between one-fifth to one-quarter in many economies, with consumer expenditure potentially dropping by around one-third. This is far greater than anything experienced during the 2008 financial crisis. And this estimate only covers the initial direct impact in the sectors involved and does not take into account any additional indirect impacts that may arise. Nonetheless, it is clear that the impact of the shutdowns imposed on many economies will weaken short-term growth prospects substantially, equivalent to a decline in annual GDP growth of up to 2 percentage points for each month that strict containment measures are imposed. If the shutdown continued uninterrupted for 3 months, with no offsetting factors, annual GDP growth could be between 4 and 6 percentage points lower than it otherwise might have been. However, the worst potential impacts may be offset by measures such as the USD \$5 trillion in fiscal spending the G20 countries agreed to inject into the global economy at their summit on March 26, 2020.

The Covid-19 epidemic and measures to counteract it are likely to disproportionally affect poorer people. The OECD's "How's Life?" 2020 shows that overall, 36\% of people in OECD countries are financially vulnerable, meaning they would lack the financial assets needed to avoid falling into poverty if they were to lose 3 months of their income. This figure climbs to over $60 \%$ in some OECD countries. Those working in the "gig economy" are the most exposed. These workers often work on short contracts, sometimes with weak or no social protections, with limited options for working remotely, and with risks of job loss and forgone earnings if they have to remain away from their place of work due to illness, quarantine, or government-mandated closures of specific activities. Anti-virus measures will affect them significantly since they are often employed in occupations demanding a high degree of contact with a wide range of clients, such as restaurants, taxis, and delivery services.

Measures to compensate people and firms for lost earnings are being introduced to alleviate the situation. These can include postponement of taxes and debt repayments and government paid leave for people in countries which do not have paid sick leave. But in countries where there are short-term contracts, and poorer people have few savings, no amount of monetary stimulus will re-energize demand. The poor will be hardest hit in countries such as Indonesia, Mexico, and Brazil, with up to $50 \%$ or higher of the population employed in the informal sector and few channels through which any aid could reach such people. Oxfam estimates that the economic crisis caused by Covid-19 could push half a billion people into poverty (Oxfam 2020). However, conditional cash transfers were scaled up very effectively following the 2008 global financial crisis; even in the Least Developed Countries, food for work programs and other forms of social protection can provide some relief. As to the supply side of the economy, firms that have had to reduce their activities will take time to restart production and to contribute to global supply chains.

In the longer term, two impacts could be especially serious. The first is the impact on international relations and the vectors of globalization. The Covid-19 pandemic has reminded us bluntly of the fragility of some of our most basic human-made systems. Shortages of masks, tests, ventilators, and other essential items have left frontline workers and the general population dangerously exposed to the disease itself. At a wider level, we have witnessed the cascading collapse of entire production, financial, and transportation 
systems, due to a vicious combination of supply and demand shocks.

China's merchandise trade was down $17 \%$ in the first 2 months of the year. While trade may rebound when the situation improves, there may be longer term, structural effects: firms may retreat from globalization, seeking shortened supply chains and suppliers located in countries that seem less prone to disruption. This would have consequences for production structures, jobs, and income in different parts of the world. This is worrying when international cooperation is literally vital in coordinating the response to Covid-19 and future systemic threats. Unfortunately, the mechanisms that might provide a coordinated international response do not exist, except for limited monetary arrangements.

The international financial system is already seeing the impacts of Covid-19, with increased volatility and sharp drops in share prices. If these falls are the beginning of a longer downward trend, there will be a direct negative wealth impact on asset holders. This may affect funded pensions and pensioners' living standards. Further easing of monetary policies by central banks (especially by the European Central Bank where deposit rates are already negative) may reinforce the income effect for pensioners or push savers to higher- risk investments. On the other hand, low interest rates may further fuel inflation in assets that are considered safe havens (e.g., real estate, gold, government bonds) making inequalities in wealth worse.

Once again, the shadow of 2008 falls over the outlook today. The IMF's Global Debt Database shows that total global debt (public plus private) reached USD $\$ 188$ trillion at the end of 2018, up by USD $\$ 3$ trillion compared to 2017 (and up by over USD $\$ 90$ trillion from 2007). The global average debt-to-GDP ratio (weighted by each country's GDP) edged up to $226 \%$ in $2018,1 \frac{1}{2}$ percentage points above the previous year (IMF 2020). Despite efforts to reduce fiscal deficits, many governments still have high levels of debt following their interventions to deal with the financial crisis and its aftermath, and sovereign spreads for some countries are starting to widen. Private debt, encouraged by low interest rates, is even more worrying. In advanced economies, IMF data show that the corporate debt ratio has gradually increased since 2010 and it is now at the same level as in 2008, the previous peak. In several major economies debt is, or was, increasingly used for financial risk-taking (to fund distribution of dividends, share buybacks, and mergers and acquisitions). Much of the debt is high speculative-grade debt, and a significant fraction of corporate debt is now rated BBB, the lowest investment grade rating. Almost half of all US corporate bonds maturing in the next 5 years are below investment grade. Global household debt is over USD $\$ 47$ trillion, compared to USD $\$ 35$ trillion going into the 2008 crisis.

\section{Complex system view on the Covid-19 outbreak}

In a linear, Newtonian world, actions cause predictable reactions. Today's complex system of environmental, socio-political, and economic systems, however, is constantly being reconfigured by human behavior and is simultaneously constantly affecting that behavior. In such a world, a small change can be transmitted and amplified by the interconnectedness of the system to have enormous consequences, far beyond the time, place, and scale of the initial perturbation. In 2007-2008, problems in a national home loans market escalated into a financial crisis that almost destroyed the global banking system. The consequences of the 2008 crisis were still being felt 10 years later because it provoked an economic recession that in turn caused political and social upheaval.

The Covid-19 crisis is another illustration of how systems change each other. The initial cause, as in previous coronavirus outbreaks, was transmission from animals to humans of a virus. When we look in more detail at how this happened, we will probably find that a range of social, economic, and environmental changes contributed to creating conditions where zoonosis could become so damaging - for example, changing land-use patterns and agricultural practices. But we shouldn't stop at the immediate interactions. We could argue that the 2020 health crisis was made far worse by the 2008 financial crisis, or more precisely, the austerity measures that left many health systems without the basic resources such as protective clothing needed to cope with a sudden, unexpected upsurge in the number of patients.

Covid-19 also shows how subjective factors such as trust in institutions and willingness to follow their advice and instructions, or the sentiment of belonging to a community, can influence how a disaster unfolds. A full understanding of such factors requires an approach based on integrative economics, which calls on the insights and methods of the range of disciplines needed to paint a realistic picture of how the economic system is shaped and helps shape the larger "system of systems" it is part of. Furthermore, systems thinking allows us to identify the key drivers, interactions, and dynamics of the economic, social, and environmental nexus that policy seeks to shape, and to select points of intervention in a selective, adaptive way. Critically, this allows us to emphasize the importance of system resilience to a variety of shocks and stresses, allowing systems to recover from lost functionality and adapt to new realities regarding international economics, societal needs, and human behavior, as well as the risks of a more unpredictable climate.

For example, the nuclear power industry in OECD countries relies on a safety philosophy known as "integrated 
defence in depth." This framework requires consideration of not just reactor design and hardware performance but also the human and organizational elements (e.g., emergency response organizations) necessary for safe reactor operation (NEA 2016). This framework, consistent with integrative economics, assesses overall system resilience, while recognizing that one must consider a variety of complex, interconnected variables. Energy supply security, a negative externality that demands a policy response from government, may offer additional insights. Most electricity systems are, as a result, resilient by law: mandatory levels of additional dispatchable capacity are kept in reserve should the output of some technologies, or individual plants, become variable.

Ferguson et al. (2020) of Imperial College, London provided simulations of Covid-19's diffusion which indicated that the United Kingdom's health service would be overwhelmed and might face 500,000 deaths if the government took no action. This led to the implementation of restrictions on social movement. Using a similar modeling approach, simulations for the United States suggested 2.2 million deaths if no actions were taken. After this prediction was shared with the White House, new guidance on social distancing was issued. Epidemiologist Joshua Epstein from New York University outlined the global spread of pandemics with a focus on Covid-19, in which the interaction between the infection dynamics (created by the pandemic) and the social dynamics (created by fear) produce volatile outcomes. $^{2}$

This includes the idea of a coupled contagion: the pandemic and fear about it (which affects health and economic behavior), and how their interactions produce volatile dynamics. Individuals contract fear through contact with the disease-infected (the sick), the fear-infected (the scared), and those infected with both fear and disease (the sick and scared). Scared individuals - whether sick or not- withdraw from circulation with a certain probability, which affects the course of the disease epidemic proper. If individuals recover from fear and return to circulation, the disease dynamics become rich, and include multiple waves of infection, such as occurred in the 1918 Influenza Pandemic (Epstein 2014). One could push the argument further, using the example of the financial system. The two epidemics, contagion and fear, operate in tandem and the behavior of individuals is changed. The movements in capital markets engendered by the change in decisions of market participants, who were originally affected neither by the virus nor

\footnotetext{
2 Another very clear and interesting contagion model, highlighting the role of social dynamics, lags, and threshold effects in recurrent waves of measles in Africa (due in part to lulls in vaccination) is found in Schelling (1999).
}

by fear of it, may set off an epidemic of market movements. This can lead, as we have observed recently, to a crash of unprecedented proportions.

\subsection{Strategies and policies to increase resilience}

So, how should we deal with the considerable shock that Covid-19 places upon international markets, public health, social activity, and governance? How can we address the cognitive and especially behavioral effects of fear at the individual and collective level which can trigger substantial slowdowns in economic activity, as well as the systemic effects that strain various sectors of international trade and governance?

Two overarching philosophies and methodologies are available for stakeholders to draw upon. Until recently, the consensus would have insisted upon preventing a threat from happening in the first place or, if absolute prevention or avoidance were impossible, upon substantially mitigating the consequences of the threat. As the basis of conventional risk management (i.e., to prepare for and absorb shocks), this option is politically appealing at the onset, as it offers the possibility that unacceptable risks may be mitigated before they cause serious problems. ${ }^{3}$ In a world of rapid feedback loops and increasingly nested systems where cascading failures are inevitable, however, such options might be ineffective at protecting economic and social systems and calming perturbations, or would be ruinously expensive to implement to the extent needed to assure policymakers and other stakeholders of adequate protection (Michel-Kerjan 2012; Linkov et al. 2019).

The second approach is one that accepts the inherently uncertain, unpredictable, and even random nature of systemic threats and addresses them through building system resilience. Rather than rely solely upon the ability of system operators to prevent, avoid, withstand, and absorb any and all threats, resilience emphasizes the importance of recovery and adaptation in the aftermath of disruption. Such a mind set acknowledges that the infinite universe of future threats cannot be adequately predicted and measured, nor can the effects thereof be fully understood. Resilience acknowledges that massive disruptions can and will happen-in the future, for example, climate disruption will likely compound other shocks like pandemics - and it is essential that core systems have the capacity for recovery and adaptation to ensure their survival into the future, and even take advantage of new or

\footnotetext{
3 This is not to discount the importance of risk management. A stronger risk approach would, for example, have led to complete development of a SARS vaccine, on the grounds that a coronavirus outbreak of some sort was likely at some point, and the costs of completion would have been trivial in comparison.
} 
revealed opportunities following the crises to improve the system through broader systemic changes. ${ }^{4}$ This is sometimes characterized as not just bouncing back, but "bouncing forward" (Linkov et al. 2018a, b; Ganin et al. 2016, 2017).

Covid-19 is the latest instance of an unpredictable shock to interconnected systems, where international recovery will have vast implications for future economic, social, and governmental activity. Resilience must become a core philosophy within system management and operation to ensure we are able to continue to function despite disruptions like Covid-19, and are able not only to adapt and improve in its aftermath, but to seize upon new or revealed opportunities. ${ }^{5}$

Interconnectivity between systems is one of the structuring and determining features of our modern world, which is becoming ever more complex and dynamic. This is a product of economic opportunity as well as global political interconnectedness, and has brought considerable benefits to much of the global population. An instinctive reaction to the Covid-19 outbreak would be to limit or reduce such interconnectedness, yet such sweeping policy changes would not better protect countries or international markets against future systemic threats. Instead, an emphasis upon developing resilience within the international economic system is a necessary evolution for a post-Covid-19 world, where systems are designed to facilitate recovery and adaptation in the aftermath of disruption.

Complementing risk-based approaches with resiliencebased approaches for management of epidemics, as well as for other systemic threats, is a necessity. The resilience we are talking about here, however, is not resilience in the traditional sense, meaning the capacity to resist downturns and get back to the same situation as before. There is an awareness that the systemic threats modern societies face are increasingly difficult to model, and are often too complex

\footnotetext{
${ }^{4}$ For example, the protective function of buffers, the psychological and organizational functions of slack (see Shafir and Mullainathan), or the adaptive function of redundancy by design (there are many examples of this in biology and engineering).

${ }^{5}$ For example, under the French G20 Presidency, and in the context of a global food price crisis (that saw the price of many of the important food commodities double), the UN Food and Agriculture Organization (FAO) and the OECD led a group of ten IOs to recommend creation of an Agriculture Market Information System (AMIS). This recommendation was agreed upon by leaders, subsequently implemented, and has been operating for almost a decade. This system brings together market expertise (mostly from FAO) and policy knowledge (mostly from OECD), a Market Information Group (country representatives, mandated to ensure timely exchange of market insights), and a Rapid Response Forum (senior country representatives, supported by IOs, tasked with addressing emergency situations in real time - to avoid a crisis, or at least mitigate its severity). AMIS proved its value by averting a near-crisis in its first year of operation, and is active at this moment monitoring markets and policies, and engaging with countries to facilitate informed decision-making and avoidance of bad policy choices
}

to be solved for the "optimal response" using traditional approaches of risk assessment that focus primarily upon system hardness and ability to absorb threats before breaking. The new approach to resilience will focus on the ability of a system to anticipate, absorb, recover from, and adapt to a wide array of systemic threats (see Figure 1).

Linkov et al. (2019) identify systemic threats and review the analytical and governance approaches and strategies to manage these threats (including epidemics) and build resilience to contain their impacts. This aims to help policymakers build safeguards, buffers and ultimately resilience to physical, economic, social and environmental shocks.

Fundamentally, Covid-19 is a multi-system problem. Beginning with a slow yet unchecked spread of disease on a global scale, it quickly disrupted hospital systems and associated resource and labor requirements. Simultaneously, as socioeconomic activity waned per government orders for quarantine and shelter-in-place, systemic disruption spread beyond the public health domain and into energy (fossil fuels), economics and finance, and even the broader political systems of various states. The loss of functionality triggered by this single disruption origin is one that requires robust recovery to minimize extensive and even permanent multisystem losses and damages (see Fig. 1) - a lesson learned from the aftermath of the Great Recession.

\subsection{Recovery and adaptation in the aftermath of disruptions}

Recovery and adaptation in the aftermath of disruptions is a requirement for interconnected 21 st century economic, industrial, social, and health-based systems, and resilience is an increasingly crucial part of strategies to avoid systemic collapse (Merad and Trump 2020). Based on OECD reports and the resilience literature, specific recommendations for building resilience to contain epidemics and other systemic threats include:

- Design systems, including infrastructure, supply chains, economic, financial, and public health systems, to be resilient, i.e., recoverable and adaptable.

- Develop methods for quantifying resilience so that tradeoffs between a system's efficiency and resilience can be made explicit and can guide investments.

- Control system complexity to minimize cascading failures resulting from unexpected disruption by decoupling unnecessary connections across infrastructure and making necessary connections controllable and visible.

- Manage system topology by designing appropriate connections and communications across interconnected infrastructure.

- Add resources and redundancies in system-crucial components to ensure functionality. 
Fig. 1 COVID-19 disruption as a multi-system challenge. Where the threats, exploited vulnerabilities, and consequences of COVID-19 continue to manifest around the globe, extensive consideration must be given not only to how risk is absorbed and mitigated, but how affected systems will recover, adapt, and preferably "bounce forward" toward a more ideal system state (after Trump et al. 2020)

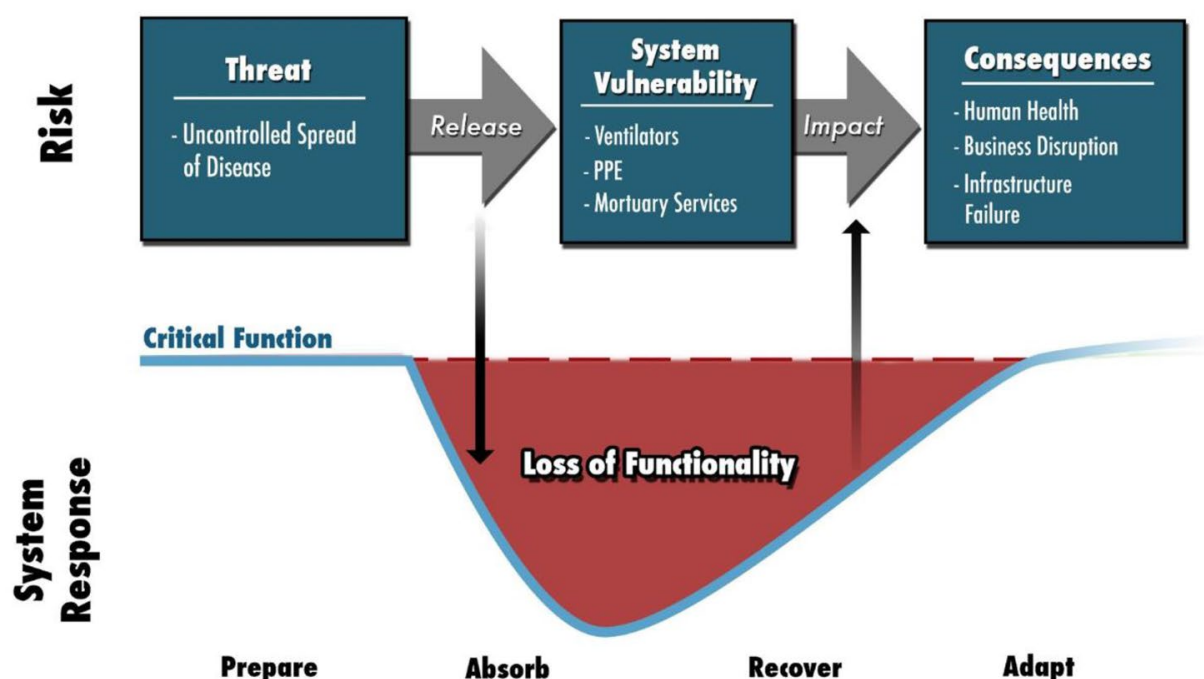

Prepare
Absorb
Recover
Adapt
- Develop real-time decision support tools integrating data and automating selection of management alternatives based on explicit policy trade-offs in real time.

Procedurally, a complement to such resilience-based approaches is included in the International Risk Governance Centre's Guidelines for the Governance of Systemic Risks (IRGC 2018). The IRGC highlights a multi-step procedure to identify, analyze, and govern systemic risks, as well as better prepare affected systems for such risks by mitigating possible threats and transitioning the system toward one of resiliency-by-design. As a cyclical process, the IRGC's process for the governance of systemic risk includes:

1. Explore the system, define its boundaries and dynamics.

2. Develop scenarios considering possible ongoing and future transitions.

3. Determine goals and the level of tolerability for risk and uncertainty.

4. Co-develop management strategies dealing with each scenario.

5. Address unanticipated barriers and sudden critical shifts.

6. Decide, test, and implement strategies.

7. Monitor, learn from, review, and adapt.

The purpose of IRGC's exercise is not to generate a deterministic model that applies to any and all systems - this is neither possible nor helpful. Instead, it is designed to produce more introspective, collaborative, and multi-system viewpoints regarding the threats that may be lingering along the peripheries of our systems, as well as where our system's critical functions or resilience challenges should be improved within future strategic management opportunities.

An example of applying similar approaches to disease epidemics is presented in Massaro et al (2018). The methodological resilience framework discussed above was applied to the analysis of the spread of infectious diseases across connected populations. Massaro et al. monitor the system- level response to the epidemic by introducing a definition of engineering resilience that compounds both the disruption caused by the restricted travel and social distancing and the incidence of the disease. They confirm that intervention strategies, such as restricting travel and encouraging self-initiated social distancing, reduce the risk to individuals of contracting the disease. There is, though, a price to pay in terms of population mobility that will inevitably have repercussions on critical functionality, thus making the system less resilient, unless this is factored in to lockdowns, curfews, and other responses.

So although containment measures are unavoidable to slow down the epidemic's progression, such measures may drive the system into negative health and economic outcomes. Multiple dimensions of a socio-technical system must be considered in epidemic management. Massaro et al. set out a framework for analyzing contingency plans at the national and international levels (2018). For Covid19 , this implies that countries should resist the temptation to self-isolate from their international partners in an attempt to build national self-reliance. Viruses do not respect borders or administrative silos and the response to them has to be international and inter-sectoral. The encouraging examples of medical equipment, personnel, best practices, and even hospital capacity being shared among countries can motivate and justify an integrated, multilateral approach to helping national and international systems to bounce forward and emerge from the crisis in a far better state than before. The cooperation and mechanisms to encourage recovery and adaption that emerged in tackling Covid-19 should not be allowed to fade when the crisis ends. 
Governments are considering a wide variety of political and economic policies to safeguard and recover economic and societal functions lost due to the Covid-19 pandemic. It will be important to frame strategic opportunities to shape intermediate and future policy in a manner that not only preserves normatively beneficial systems and recovers from this crisis, but also frames national and international economic systems. Policy actions to facilitate recovery must be analyzed and selected now (Trump et al. 2020). Any policy decisions in the short term will shape not only the nature of economic recovery in the next year, but the economic and political priorities of economic globalization as well. ${ }^{6}$ Policy choices made for the recovery will also have a strong influence on the world's ability to avert dangerous climate change, as well as to become more resilient to the climate impacts already locked in.

In recovering from the Covid-19 shock, policymakers can use economic models and other analytical resources to assess the efficiency of different regulatory policies discussed in Box 1. The immediate health, economic, and social needs are of critical importance, but developing strategic priorities and building resilience in national and regional responses to the crises will be equally important. In both cases, policy interventions and priorities to address Covid-19 must incorporate principles of system resilience to systemic disruption now, for not doing so will limit socioeconomic recovery for the next decade.

Systems thinking is the most powerful tool we have at our disposal to accomplish this task, so long as it is part of a trilogy completed by anticipation and resilience. On a theoretical level, systems thinking shows that crises are an intrinsic characteristic of complex systems such as public health or financial markets. In practical terms, policymakers must factor in the certainty that sooner or later all systems fail, including the ones for which they are making policy. Policymakers must be prepared for this eventual failure, even if preparation does not appear to be cost effective until after the crisis has happened. The excuse that dangers are clear only in hindsight does not stand up to objective scrutiny. Major simulation exercises in OECD countries predicted

\footnotetext{
${ }^{6}$ Just as in advanced economies, governments in developing countries need to take swift action; however, their institutional and fiscal capacities are limited. The crisis has exposed an aspect of fiscal policy in developing countries that was previously less examined: their resilience. Timely international coordination to enable developing countries to face the crisis with the economic packages needed will be fundamental in the short- to medium- term. The financial pressure that economic packages will put on fiscal systems should not be under-estimated. Most developing countries face high levels of informality - both workers and firms - requiring innovative channels to reach the vulnerable population in times of crisis.
}

accurately how a crisis like Covid-19 could unfold, ${ }^{7}$ but they were not acted upon, or at least not sufficiently, judging by what has happened.

No two crises are identical, but they can all offer useful lessons for the next time. Some countries, such as Korea, drew on past experience to react quickly to the new coronavirus threat. Korea was helped by the fact that its hospital system has a high number of intensive care beds, indeed higher than many health system managers would consider cost-efficient. But extra capacity increases resilience. In health and other physical domains, an emphasis on resilience can be easily recognized as cost effective, given the enormous costs of investing in the infrastructures and other resources that would be needed to prevent planetary emergencies such as serious floods, droughts, or other disasters provoked by climate change (Linkov \& Trump 2019).

Resilience is also a safe option in intangible domains such as financial systems. Plenty of people saw the present financial crisis coming and many experts pointed to debt as a major contributing factor to system fragility. A policy approach based on systems thinking would accept that although we do not know what the trigger of the next crisis will be, we do know it will come and that certain factors can make it more likely and more damaging, and that there are better policy options than waiting for it to happen and then paying for bailouts.

Finally, a systems approach will help "break down silos". We are seeing how a health crisis does not remain simply a health crisis for long. It can quickly spread to other systems that at first sight seem to be unconnected. In a world where an ecosystem in a Chinese province can trigger a global economic crisis, we have to abandon our traditional, linear, compartmentalized way of making and applying policy, and cooperate pragmatically at local to international levels.

\subsubsection{Box 1. Strategic policy interventions for COVID-19}

(1) Recovery and building resilience in the local economy

Strategic need Preserve and Recover from Disruptions to Local Economies.

Policy response Identify interventions to improve business recovery post-Covid-19. Funding should be prioritized based on immediate needs for economic recovery at the system level,

${ }_{7}$ For example, Crimson Contagion in the US or Exercise Cygnus in the UK. 
including a consideration of local demand, of the regional /global supply chain, and of the impact of the region in question on regional, state, and global economy.

Economic action Prioritize and invest in critical economic sectors and businesses based upon value-added to local community (i.e., the dollar/euro yielded for taxes, salaries, local spending per dollar/euro invested in the company).

Actions needed Assist governments (both national and local) in prioritizing (a) critical economic sectors and (b) critical industries/businesses that have a socially and economically netpositive contribution to society. Any low-interest loans or targeted investments/disbursements should be targeted here, rather than prioritizing businesses or industries with social or economic net negatives/ harms to broader society (i.e., high downstream costs with low immediate benefits via exploitative wages and sending money outside of the local economy).

(2) Household resilience

$\begin{array}{ll}\text { Strategic need } & \begin{array}{l}\text { Bolster Consumer/Household Resil- } \\ \text { ience to Shock. }\end{array} \\ \text { Policy response } & \begin{array}{l}\text { Identify interventions to improve } \\ \text { household recovery post-Covid-19. }\end{array} \\ & \text { As the core of economic growth, } \\ \text { individual households need to be } & \text { provided resources/support at the } \\ & \text { system level across necessary goods, } \\ & \text { services, and social/cognitive sup- } \\ \text { port. Optimization should be based } \\ \text { on individual/community resilience } \\ \text { to avoid the impact of shocks and to } \\ \text { optimize recovery. }\end{array}$

Economic action Revisit recommended assumptions regarding household budgets, and identify areas of required slack/ redundancy in household spending/ savings.

Actions needed First, analyze government stimulus proposals based upon their ability to meet all or most of the critical household needs of various segments of the population disrupted by the crisis. Second, adopt recommendations to prevent household brittleness or fragility to shock (high cost of core essentials like housing, food, utilities, education, public health, etc.). Identify governmental investments and policy options to mitigate rising cost concerns of core industries and incentivize "slack," or household savings, to accommodate disruption of lost wages.

(3) Company/business resilience

Strategic need Prevent Company Bankruptcy, Layoffs, and/or Shutdown While Complying With Pandemic Response Requirements.

Policy response Identify critical companies whose disruptions and layoffs would reduce national capacities to deliver goods and services in a non-linear fashion (i.e., lost synergy, social capital, institutional memory, etc.)

Economic action Targeted loans and investments into select companies and large corporations whose disruptions are not easily recoverable, and whose losses in institutional memory/social capital would have long-term ramifications.

Actions needed Identify industries which historically have had difficulties in recovery post-disruption (e.g., the " Dot Com Bubble," the September 11th terrorist attacks, the financial crisis/ Great Recession of 2007-2009, etc.). Within those industries, identify economic interventions (low/zerointerest loans or other investments) that have policy requirements of keeping sections of their labor force on payroll throughout the crisis and during recovery. Require the company to cover a portion of its payroll (e.g., one day each week), with government investments covering the majority of the payroll (e.g., one days each week). Labor covered by government investment should be in full compliance with WHO recommendations regarding social 
distancing and pandemic response requirements. This proposal will (a) prevent mass layoffs at highintensity corporations that require considerable institutional and technical knowledge to operate, and (b) remove the need for workers at such corporations to seek new economic opportunities for lost wages while ensuring they remain in compliance with pandemic response requirements.

\section{Conclusions}

Economic analysis is often the most important tool for policymaking, but given that the socioeconomic system is changing and self-organizing itself in a way which is difficult, if not impossible, to reconcile with existing theory, economics has to change too. In an increasingly complex and interdependent system, the aggregate phenomena that emerge do so as a reflection of the interaction between all the participants. The system is constantly evolving and is neither in, nor converging toward, a steady state. Policy cannot be based on extrapolations from the past or analysis of the behavior of an isolated individual.

System-analysis models have to improve too, to better integrate real-world dynamics such as social and behavioral heterogeneity. This will help to represent social dynamics and complex collective decision-making and facilitate the evaluation of the effectiveness of policies and their systemic impacts. A promising approach is to integrate existing modeling tools from different fields, for example linking environmental models with economic growth and trade models. This extends the boundaries of what is modeled and allows for broader ranges of interactions to assess policy interventions. Going beyond the integration of existing tools may involve pioneering applications and innovative methodologies and tools in several areas, including explicit accounting for uncertainty, multiple agents with strategic interactions, bounded rationality, including consumption preferences and consumer choices, and network effects linked to complex interconnectedness and systemic risks.

A fundamental challenge to governing systemic risk is understanding the system as a complex network of individual and institutional actors with different and often conflicting interests, values, and worldviews. Superimposed on this governance network are the potential risk events with ill-defined chains or networks of interrelated consequences and impacts. A resilience mind set acknowledges that the infinite variety of future threats cannot be adequately predicted and measured, nor can their effects be fully understood. Adopting such an approach means rethinking our priorities, and especially the roles of optimization and efficiency. The science of systems engineering teaches us that when you try to optimize one part of a complex system, you can end up destabilizing the system as a whole. This principle is evident in global supply chains, surely one of the most efficient components of the international economy. The French Minister for the Economy, Bruno Le Maire, argues that that there will be a before and after Covid-19 for the world economic system: "We need to draw all the conclusions from this epidemic on the way globalization is organized, and notably value chains" (Le Maire 2020). When your highly optimized workflow is disrupted by shocks such as Covid-19, maybe just-in-time needs a dose of just-in-case.

In 2015, Bill Gates said, "We are not prepared for the next outbreak," and suggested creating an army of specialists from many disciplines to meet whatever crisis or epidemic might arise. 27 million people viewed the talk in which he made this comment, but as he noted in 2020, nobody in power heard the message. We are now in the midst of a systemic upheaval. In the spirit of Gates' call, international policymaking should look to better anticipate, prepare for, and build resilience for future crises.

The radical uncertainty associated with complex systems makes it impossible to predict where the next crisis will come from; nevertheless, this should not stop us learning the lessons of the past to prepare a systemic response for the future. One lesson from Covid-19 is that crises do not repeat themselves. The fact that we were able to contain previous coronavirus crises such as SARS led to a sense of complacency in some instances about our ability to contain any future crisis. We cannot afford to be complacent about the other grave crisis we are facing: the climate emergency. In systemic terms, this is not a shock, with all that implies of a sudden, unexpected occurrence, but more like a stress. Systems analysis teaches us that stresses such as global warming are non-linear. The system may continue to function more or less normally for a long period and only degrade slowly, but it can then reach a tipping point from which it cannot recover, and collapse can then be extremely rapid. Covid19 shows that we have to act now, because we simply don't know how changes in one system may evolve and impact other systems, or in this case how a mutation in a virus could cripple the world economy. We can anticipate, however, that serious damage to a natural system, such as biodiversity loss, or significant changes, such as sea level rise or increased occurrence of extreme weather, will have serious impacts on economic and social systems too. Further, as we recover and reconfigure systems for a brighter future, we must be cognizant of the fact that future systemic shocks may arise from any number of origins or industries, with no reasonable way 
to anticipate and prepare for the broad universe of threats. Instead, our systems must be designed for resilience, providing them with the capacity for recovery and adaptation regardless of the challenges they may face.

\section{Compliance with ethical standards}

Conflict of interests The authors declare that they have no conflict of interest.

\section{References}

Aubin JP (2010) Une approche viabiliste du couplage des systèmes climatique et économique. Nat Sci Soc 18:277-286

Epstein J (2014) Agent_Zero: toward neurocognitive foufor generative social science. Princeton University Press, Trenton

Ferguson NM et al. (2020) Preprint at Spiral https://doi.org/10.25561 177482

Fujimoto T (2011) Supply Chain Competitiveness and Robustness: A Lesson from the 2011 Tohoku Earthquake and Supply Chain 'Virtual Dualization'. MMRC Discussion Paper Series, N`362, https://merc.e.u-tokyo.ac.jp/mmrc/dp/pdf/MMRC362_2011.pdf

Ganin AA, Kitsak M, Marchese D, Keisler JM, Seager T, Linkov I (2017) Resilience and efficiency in transportation networks. Sci Adv 3(12):e1701079

Ganin AA et al (2016) Operational resilience: concepts, design and analysis. Sci Rep 6:19540

Golan MS, Jernegan LH, Linkov I (2020) Trends and applications of resilience analytics in supply chain modeling: systematic literature review in the context of the COVID pandemic. Environment, Systems and Decisions.

Haldane, Andrew G. (2009) Rethinking the financial network. BIS Review, https://www.bis.org/review/r090505e.pdf

Systemic risks in society and economics. In: Social self-organization, Springer, Berlin

IMF (2020) Global Debt Database https://www.imf.org/external/datam apper/datasets/GDD

IRGC (2018), Guidelines for the Governance of Systemic Risks: In systems and organisations In the context of transitions. ETH Zurich

Johnson CK et al (2020) Global shifts in mammalian population trends reveal key predictors of virus spillover risk. Proc R Soc B 28720192736: https://doi.org/10.1098/rspb.2019.2736

Linkov I, Trump BD, \& Hynes W (2019) Resilience strategies and policies to contain systemic threats

Linkov I, Trump BD, Poinsatte-Jones K, Love P, Hynes W, Ramos G (2018) Resilience at OECD: current state and future directions. IEEE Eng. Manage. Rev. 46(4):128-135

Linkov I, Trump BD (2019) The science and practice of resilience. Springer, Berlin
Linkov I, Trump BD, Keisler J (2018) Risk and resilience must be independently managed. Nature 555(7694):30-30

Marchese, K (2012), Bouncing back: supply chain risk management lessons from post-tsunami Japan. Industry Week.

Michel-Kerjan E (2012) How resilient is your country? Nat News 491(7425):497

Juttner U, Maklan S (2011) Supply chain resilience in the global $€$ financial crisis: an empirical study. Supply Chain Manag 16(4):246-259

Massaro E, Ganin A, Perra N, Linkov I, Vespignani A (2018) Resilience management during large-scale epidemic outbreaks. Nat Sci Rep. 8:1859

Merad M, Trump BD (2020) Expertise under scrutiny. Springer International Publishing, New York

NEA (2016) Implementation of defence in depth at nuclear power plants: lessons learnt from the Fukushima Daiichi accident nuclear regulation. OECD Publishing, Paris

OECD (2011) Divided we stand: why inequality keeps rising. OECD Publishing, Paris

OECD (2016) PISA 2015 results (volume I): excellence and equity in education. OECD Publishing, Paris, PISA

OECD (2018) A broken social elevator? How to promote social mobility. OECD Publishing, Paris

OECD (2020) OECD economic outlook, interim report March 2020: Coronavirus, the world economy at risk. OECD Publishing, Paris

OECD/FAO (2019) Background Notes on sustainable, productive and resilient agro-food systems: value chains, human capital, and the 2030 Agenda. OECD Publishing, Paris

Oxfam (2020) Dignity not destitution, an economic rescue plan for all.https://www.oxfam.org/en/research/dignity-not-destitution

Le Maire (2020), Coronavirus: Il y aura, dans l'histoire de l'économie mondiale, un avant et un après coronavirus. déclare Bruno Le Maire" https://www.francetvinfo.fr/sante/maladie/coronavirus/ coronavirus-il-y-aura-dans-1-histoire-de-l-economie-mondialeun-avant-et-un-apres-coronavirus-declare-bruno-le-maire_38586 03.html

Rohr JR et al (2019) Emerging human infectious diseases and the links to global food production. Nat Sustain 2:445-456. https://doi. org/10.1038/s41893-019-0293-3

Schelling, T. (1999) Social mechanisms and social dynamics. In Social mechanisms: An analytical approach to social theory. In: Hedström P, Swedberg, R (eds.). pp. 32-44. Cambridge University Press, Cambridge

Trump BD, Bridges T, Cegan J, Cibulsky S, Greer S, Jarman J, Lafferty B, Surette M, Linkov I (2020) An analytical perspective on pandemic recovery. Health Security.

Trump, B., Keisler, J., Volk, K., \& Linkov, I. (2020). Biosecurity Demands Resilience. Environmental Science \& Technology,54, 4706-4708. 